\title{
Establishment of Highly Tumorigenic Human Gastric Carcinoma Cell Lines from Xenograft Tumors in Mice
}

\author{
Kyung-A Song ${ }^{1}$, Jihyun Park ${ }^{2}$, Ha-Jung Kim ${ }^{3}$, Myung Soo Kang ${ }^{4, \dagger}$ and Sun Young Kim ${ }^{3, \dagger}$ \\ ${ }^{I}$ Philips Institute for Oral Health Research, Virginia Commonwealth University School of Dentistry, Richmond, VA23298, \\ ${ }^{2}$ Department of Health Sciences and Technology, SAIHST, Sungkyunkwan University, Seoul 06351, Korea \\ ${ }^{3}$ Department of Medicine, Division of Hematology-Oncology, Samsung Medical Center, \\ Sungkyunkwan University School of Medicine, Seoul 06351, Korea \\ ${ }^{4}$ Institute of Life Technology, Intron Biotechnology Inc., Seongnam 13202, Korea
}

\begin{abstract}
Patient's primary tumor-derived tumor cell lines likely represent ideal tools for human tumor biology in vitro and in vivo. Here, we describe eight human gastric carcinoma cell lines derived from established tumors in vivo upon subcutaneous transplantation of primary gastric carcinoma specimens in BALB/c nude mice. These xenografted gastric tumor cell lines (GTX) displayed close similarity with primary gastric tumor tissues in their in vivo growth pattern and genomic alterations. GTX-085 cells were resistant to cisplatin, while GTX-087 was the most sensitive cell line. GTX-085 was the only cell line showing a metastatic potential. Epithelial cell adhesion molecule (EPCAM) expression was especially strong in all tissue samples, as well as in cell cultures. GTX-139, the largest tumor graft obtained after injection, displayed distinct expression of CD44v6, fibroblast growth factor receptor 2 (FGFR2), and prominin 1 (PROM1, also known as CD133). In summary, we established eight xenograft gastric cancer cell lines from gastric cancer patient tissues, with their histological and molecular features consistent with those of the primary tumors. The established GTX cell lines will enable future studies of their responses to various treatments for gastric cancer.
\end{abstract}

Key Words: Gastric cancer, Xenograft, Cell line, FGFR2 amplification, Targeted therapy

\section{INTRODUCTION}

Although the gastric carcinoma (GC) mortality rate has decreased worldwide, it is still high in Korea $(43 / 100,000)$, especially among men (Shin et al., 2004; Ushijima and Sasako, 2004). Metastasis is the major cause of gastric cancer death (Shridhar et al., 2013). Therefore, thorough understanding of the biological nature of gastric cancer is vital to develop proper therapeutic methods and to improve the current prognosis of the disease. To achieve these goals, permanently growing cell lines derived from cancer patients may play an invaluable role in research studies.

Cancer cell lines are established from pathologically proven gastric tumors, either directly or after xenotransplantation to athymic nude mice (Park et al., 1990). Although GC has

* Received: July 19, 2017 / Revised: August 23, 2017 / Accepted: August 24, 2017

${ }^{\dagger}$ Corresponding author: Sun Young Kim. Department of Medicine, Division of Hematology-Oncology, Samsung Medical Center, Sungkyunkwan University School of Medicine, Seoul 06351, Korea.

Tel: +82-2-2148-7293, Fax: +82-2-3410-7385, e-mail: enthalpy98@gmail.com

Corresponding author: Myung Soo Kang. Institute of Life Technology, Intron Biotechnology Inc., Sagimakol-ro 137, Jungwon-gu, Seongnam, Gyeonggi-do 13202 , Korea.

Tel: +82-31-739-5315, Fax: +82-31-739-5353, e-mail: msk915@intron.co.kr

(C) The Korean Society for Biomedical Laboratory Sciences. All rights reserved.

(c) This is an Open Access article distributed under the terms of the Creative Commons Attribution Non-Commercial License (http://creativecommons.org/licenses/by-nc/3.0/) which permits unrestricted non-commercial use, distribution, and reproduction in any medium, provided the original work is properly cited. 
been considered to be very difficult to culture (Park et al., 1990), more than 36 gastric cancer cell lines have been established to date, mostly from Japan and Korea, where gastric cancer mortality rates are still very high (Ushijima and Sasako, 2004; Ku et al., 2012). Established cell lines were derived either from ascites of patients with signet-ring cell GC (Yanagihara et al., 1991) or from human primary and metastatic GCs (Park et al., 1990; Park et al., 1997), and there have been few reports of spontaneous metastasis from human gastric tumor xenografts in nude mice (Yanagihara et al., 2004). Thus, it has been reported that two human signet-ring cell GC cell lines exhibited the ability to spontaneously metastasize to lymph nodes and lungs in nude mice (Yanagihara et al., 2004) and three gastric cancer cell lines derived from the liver showed a metastatic potential for the liver, lung, lymph nodes, and peritoneum (Nakanishi et al., 2005). However, the availability of cell lines to investigate the heterogeneity of GCs is still limited.

In 2007, advantages of the establishment of a cancer cell line from a tumor fragment through a xenograft stage, rather than directly from a primary tumor, were first demonstrated for colon carcinoma (Dangles-Marie et al., 2007). The authors claimed that it was technically difficult to obtain representative human colon cancer cell lines from fresh tumors. In particular, it was shown that a prior xenograft increased the efficiency of the cell line establishment compared with that of the direct establishment from fresh tumors (DanglesMarie et al., 2007). Moreover, human colon cancer cell lines derived from the same tumor fragment using the two protocols displayed similarity in major phenotypic and genotypic characteristics such as the ability to form compact spheroids, karyotype alterations, and distinctive additional chromosomal aberrations, as well as in the expression levels of genes selected for their role in oncogenesis (DanglesMarie et al., 2007). Although Daniel and coauthors (Daniel et al., 2009) argued that a number of tumor-specific genes expressed in primary small-cell lung cancer and xenografts were lost during the transition to tissue culture and not regained when the tumors were reestablished as secondary xenografts, such changes in gene expression may be a common feature of many cancer cell culture systems. Therefore, xenotransplantation of tumor fragments in mice before the establishment of cell lines can be considered a practical method enabling the generation of novel human cancer cell lines for the investigation of cancer cell biology and providing the opportunity to reproduce the diversity of the diseases.

Epstein-Barr virus (EBV) has a pathogenic role in several lymphomas and solid cancers and is considered to cause GC (Yoo et al., 2015). EBV-associated GC comprises nearly 10\% of all GC cases worldwide (Fukayama, 2010). EBV-positive gastric cancers have been demonstrated to be more prevalent in males than in females and less likely to be found in the gastric antrum than in the cardia or body of the stomach (Young and Murray, 2003). Despite extensive studies, the mechanism underlying the gastric carcinogenesis caused by EBV remains unknown, which might be due to the lack of naturally infected EBV-positive cell lines available for studies. So far, only a few EBV-positive gastric cancer cell lines such as SNU-719, NCC-24, and YCCE1 have been established and characterized (Oh et al., 2007; Ku et al., 2012).

In the present study, we report the establishment and tumorigenic characterization of eight human GC cell lines (GTX-006, GTX-007, GTX-085, GTX-086, GTX-087, GTX103, GTX-116, and GTX-139), established from seven Korean male and one female gastric cancer patients whose ages ranged from 59 to 76 years old. All of these eight cell lines were indirectly established from xenografts after serial heterotransplantation of gastric tumors in nude mice. Seven cell lines (GTX-006, GTX-007, GTX-085, GTX-086, GTX087, GTX-116, and GTX-139) showed high in vivo tumorigenicity when injected subcutaneously, and five of them (GTX-006, GTX-007, GTX-085, GTX-116, GTX-139) also formed tumors upon injection in an orthotopic site (gastric wall) in nude mice. Interestingly, the GTX-085 cell line showed a metastatic ability to the ovary, which is rarely observed in the case of gastric cancer cell lines.

\section{MATERIALS AND METHODS}

\section{Primary tissue xenograft screening}

Twenty-two surgical specimens of primary GC were used for a xenograft model test. All patients provided written informed consent, and the collection and use of materials 
for research purposes were approved by the Institutional Review Board of the Samsung Medical Center. The tissues $\left(0.2 \mathrm{~cm}^{3}\right)$ were subcutaneously implanted into three BALB/c nude mice (Orient Bio, Inc., Gyeonggi, Korea). Xenograft tumors were established for $12 \sim 16$ weeks, and their sizes were monitored. The 22 primary tissues showed tumorigenicity 3 weeks after the mouse subcutaneous implantation. A serial passage was performed in vivo as described above, using a tumor fragment when the xenograft tumor size reached $1,000 \mathrm{~mm}^{3}$. A clinicopathological summary of the 22 tumors used for xenografts is described in Supplementary Table 1.

\section{Xenograft cell line establishment and culture}

The xenograft tumor tissues derived from primary tissues subcutaneously implanted into the mice were mechanically and enzymatically dissociated. After washing with phosphatebuffered saline (PBS), minced tissue was mixed with an enzyme cocktail containing $0.4 \mathrm{mg} / \mathrm{mL}$ collagenase (Gibco, Waltham, MA, USA A), $0.5 \mathrm{mg} / \mathrm{mL}$ DNase I (Roche, Basel, Switzerland), and $0.2 \mathrm{mg} / \mathrm{mL}$ dispase (Gibco, Waltham, MA, USA) in RPMI 1640 medium (Gibco, Waltham, MA, USA) and incubated at $37^{\circ} \mathrm{C}$ for $2 \mathrm{~h}$ with shaking. Dissociated tissue was filtered through a $40-\mu \mathrm{m}$ cell strainer (BD Biosciences, San Jose, CA, USA) and washed with PBS. Isolated cells were cultured in RPMI 1640 medium containing 10\% fetal bovine serum (FBS) and 1\% penicillin/streptomycin (Gibco, Waltham, MA, USA). Mycoplasma contamination was examined using a MycoAlert kit (Lonza, Basel, Switzerland).

\section{Array comparative genomic hybridization analysis}

Genomic DNA (gDNA) was extracted from tissue for pathology quality control using a QIAmp DNA mini kit (Cat. No. 51306, Qiagen, Hilden, Germany). The amount and quality of extracted gDNA were assessed using a Nanodrop spectrophotometer (ND-1000). Array comparative genomic hybridization $(\mathrm{aCGH})$ analysis was performed using a SurePrint G3 human CGH microarray kit $8 \times 60 \mathrm{~K}$ (Agilent, G4450A) following the manufacturer's instructions. Briefly, gDNA (500 ng) was digested with the restriction endonucleases $A l u \mathrm{I}$ and RsaI at $37^{\circ} \mathrm{C}$ for $20 \mathrm{~min}$. Then, random primers were added to the sample, and it was incubated for fluorescent labeling at $95^{\circ} \mathrm{C}$ for $3 \mathrm{~min}$ and on ice for $5 \mathrm{~min}$. Experimental gDNA and reference gDNA were incubated with labeling master mixtures containing cyanine 3-dUTP and cyanine 5-dUTP at $37^{\circ} \mathrm{C}$ for $2 \mathrm{~h}$ and at $65^{\circ} \mathrm{C}$ for $10 \mathrm{~min}$, respectively (Agilent genomic DNA enzymatic labeling kit, $\mathrm{p} / \mathrm{n}$ 5190-0449). After the incubation, samples were cleaned using an Amicon Ultra-0.5 Ultracel-30 membrane, $30 \mathrm{kDa}$ (Millipore, Billerica, MA, USA).

\section{DNA fingerprinting}

gDNA from each cell line was amplified using an AmpFiSTR identifier polymerase chain reaction (PCR) amplification kit (Applied Biosystems, Foster City, CA, USA). A single PCR amplified 15 tetranucleotide repeat loci (D8S1179, D21S11, D7S820, CSF1PO, D3S1358, TH01, D13S317, D16S539, D2S1338, D19S433, vWA, TPOX, D18S51, D5S818, and FGA) and the amelogenin sex determination marker at loci containing highly polymorphic microsatellite markers. Amplified products were analyzed using the GeneMapper 4.0 software (Applied Biosystems, Foster City, CA, USA).

\section{Cell viability assay with antitumor drugs}

5-Fluorouracil (5-FU) was obtained from Choongwae Pharma Corp. (Gyeonggi, Korea), and cisplatin was obtained from Dong-A Pharmaceutical (Seoul, Korea). Cell viability was evaluated using a CellTiter-Glo luminescent cell viability assay (Promega, Madison, WI, USA) per manufacturer's instructions. Briefly, 5,000 cells were treated with five different concentrations of 5-FU ( 0.9375 to $240 \mu \mathrm{g} / \mathrm{mL})$ and cisplatin $(0.5$ to $8 \mu \mathrm{g} / \mathrm{mL})$ in a 96 -well plate for $72 \mathrm{~h}$. Cell growth inhibition was detected as a luminescent signal of survived cells, and the concentration required to inhibit cell growth by $50 \%\left(\mathrm{IC}_{50}\right)$ was determined. Each experiment was conducted three times.

\section{Cell line xenograft assay}

Gastric tumor xenograft (GTX) cell lines were resuspended in a 1:1 mixture of Hank's balanced salt solution (HBSS; Gibco, Waltham, MA, USA) and Matrigel (BD Biosciences, San Jose, CA, USA) to give a final volume of 100 
$\mu \mathrm{L}$. Cells $\left(1 \sim 2.5 \times 10^{6}\right)$ were injected subcutaneously to 7-week-old female BALB/c nude mice (for EBV-negative cell lines) or NSG mice (for EBV-positive cell lines). Tumors were measured with calipers every 2 days (the largest length and width), and the mice were weighed. The mice were housed in filter-top cages containing a maximum of five mice per cage at a 12-h light/dark cycle and were provided free access to food and water. Tumor volumes $\left(\mathrm{mm}^{3}\right)$ were calculated using the following formula: width ${ }^{2}\left(\mathrm{~mm}^{2}\right) \times$ length $(\mathrm{mm}) \times 0.5$. For orthotropic injection, $1 \sim 2.5 \times 10^{6}$ cells resuspended in $100 \mu \mathrm{L}$ of HBSS were injected into the middle wall of the greater curvature of an anesthetized mouse. Magnetic resonance imaging was performed every week to detect tumor growth. At 6 12 weeks after the injection, the grafts were dissected and processed for further studies.

\section{Immunocytochemistry}

To determine whether novel established cell lines were of epithelial origin, we measured expression of cytokeratin by immunofluorescence. Cells were grown in RPMI 1640 medium on cover slips placed in 6-well plates. The cells were then fixed with 4\% paraformaldehyde, permeabilized with $0.25 \%$ Triton X-100, and incubated with $5 \%(\mathrm{w} / \mathrm{v})$ bovine serum albumin in PBS for $30 \mathrm{~min}$ at room temperature. The cells were immunostained using a fluorescein isothiocyanate (FITC)-conjugated anti-cytokeratin antibody (Miltenyi Biotech, Inc., Auburn, CA, USA) to visualize their immunoreactivity. The stained cells were mounted with the Prolong gold antifade reagent containing 4',6-diamidino2-phenylindole (Invitrogen, Carlsbad, CA, USA) and examined using a spectral confocal system (LSM 710, Zeiss, Oberkochen, Germany).

\section{Hematoxylin and eosin staining and immunohisto- chemistry}

A tumor mass was fixed in $4 \%$ formalin for $24 \sim 48 \mathrm{~h}$, embedded in paraffin, and sectioned at $4 \mu \mathrm{m}$. Tissues on slides were stained with hematoxylin and eosin (H\&E) for $30 \mathrm{~s}$, respectively. Serial sectioned tissue slides were deparaffinized in xylene, rehydrated in 70, 80, 90, 95, and 100\% alcohol for $5 \mathrm{~min}$, and washed with distilled water. The hydrated slides were treated with an antigen retrieval solution (Dako REAL ${ }^{\mathrm{TM}}$ target retrieval solution, $10 \times, \mathrm{pH} 6.0$ ) for $40 \mathrm{~min}$ in a water bath at $98^{\circ} \mathrm{C}$ and then blocked in a Dako REAL ${ }^{\mathrm{TM}}$ peroxidase blocking solution $\left(0.3 \% \mathrm{H}_{2} \mathrm{O}_{2}\right.$ in methanol). Sections were incubated with primary antibodies for $1 \mathrm{~h}$ at room temperature. After washing with PBS-Tween 20 (0.1 M PBS, 0.5\% Tween 20, pH 7.4), an EnVision ${ }^{\mathrm{TM}}$ detection system was used according to the manufacturer's instruction (Dako, Santa Clara, CA, USA). To obtain clear results, the following optimal antibodies were used: antiCD44v6 (Abcam, 1:200), anti-CD133/1 (Miltenyi Biotech, 1:200), anti-EPCAM (Santa Cruz Biotechnology, 1:200), anti-FGFR2 (Abcam, 1:150), and anti-THY1 (Cell Signaling Technology, 1:100).

\section{Immunoblotting}

Total proteins were isolated using a Pro-Prep protein extraction solution (Intron Biotechnology, Gyeonggi, Korea). Then, $25 \sim 30 \mu \mathrm{g}$ of protein was subjected to $10 \%$ sodium dodecyl sulfate polyacrylamide gel electrophoresis and electrotransferred onto nitrocellulose membranes. The membranes were blocked with $5 \%$ nonfat dry milk in Trisbuffered saline containing $0.1 \%(\mathrm{v} / \mathrm{v})$ Tween 20 and then probed overnight at $4{ }^{\circ} \mathrm{C}$ with CD44v6 (1:500; R\&D Systems, Minneapolis, MN, USA), FGFR2 (1:500; Abcam, Cambridge, UK), EPCAM (1:250; Santa Cruz Biotechnology, Dallas, TX, USA), THY1 (1:1,000; Cell Signaling Technology, Danvers, MA, USA), and $\beta$-actin (1:5,000; SigmaAldrich, St. Louis, MO, USA) antibodies. A horseradish peroxidase-conjugated anti-rabbit or anti-mouse $\mathrm{IgG}$ was used as a secondary antibody, and signals were detected by chemiluminescence.

\section{Statistical analysis}

To compare results, the Student's $t$-test or Mann-Whitney $U$-test was performed for independent variables, and the paired $t$-test or Wilcoxon signed-rank test was performed for related variables as appropriate, using SPSS version 15.0 (SPSS, Inc., Chicago, IL, USA). 


\section{RESULTS}

\section{Establishment of novel gastric tumor xenograft cell lines and culture}

Eight cell lines (GTX-006, GTX-007, GTX-085, GTX086, GTX-087, GTX-103, GTX-116, and GTX-139) were established from 22 xenograft tissues. Cells were dissociated from xenograft tissues of primary gastric cancer tissues and successfully cultured in 10\% FBS-supplemented RPMI 1640 media (Fig. 1A). Supplementary Table 1 shows a summary of clinicopathologic data. Interestingly, four cell lines (GTX006, GTX-007, GTX-085, and GTX-139) were poorly diferentiated tubular adenocarcinomas, whereas moderately differentiated tumors constituted more than $50 \%$ of the 22 xenografts of primary gastric cancer tissues. The in vivo passage numbers of the xenograft tissues used for cell culture were P2-P6 (Table 1). When analyzing their growth properties (Fig. 1A), GTX-006 and GTX-007 cells showed a round shape, and some floating cell aggregates were observed. GTX-085 cells grew as a round-cell monolayer, with most cells attached and some cells floating. GTX-086 cells formed an attached dense monolayer; and some roundshaped suspended cells were observed. GTX-087 cells were adherent and grew as round cells in aggregates. GTX-103 cells grew as a monolayer, and individual cells displayed a polygonal shape. GTX-116 and GTX-139 cells were round; most cells were attached, and some cells were floating as single cells. All results are described in Table 1.

\section{Identification and characterization of GTX cell lines}

To confirm that the xenograft tumors corresponded to the primary patient tumors, we conducted histological analysis and DNA fingerprinting. Based on the Lauren classification, the primary tumors of the GTX-006 and GTX-007 cell lines were of diffuse type, and those of the GTX-085, GTX-087, GTX-116, and GTX-139 cell lines were of intestinal type. The xenograft tissues used for cell line culture displayed similarity with the primary gastric tumor tissues as shown in Fig. 1B and 1C. Using DNA fingerprinting, we detected heterogeneity among 15 tetranucleotide repeat loci and the amelogenin sex determination marker between the primary gastric tumor tissues and xenograft tissues used for cell culture (Table 2). STR profile of xenograft tissues were concordant to those of the primary tissues. Based on the aCGH analysis, abnormal chromosome ploidy levels in the primary gastric tumor tissues corresponded to those in the xenograft tissues used for cell culture (Supplementary Fig. 1). In some cases (e.g., GTX-086 and GTX-103), the xenograft tissues showed more severe genomic abnormalities, indicating that xenograft tissues were more similar to tumor cells than to primary tissues. To examine the sensitivity of the novel cell

Table 1. Characteristics of GTX cell lines in vitro culture

\begin{tabular}{|c|c|c|c|c|c|c|}
\hline \multirow{3}{*}{ Cell lines } & \multicolumn{6}{|c|}{ Xenograft cell culture } \\
\hline & \multirow{2}{*}{ Lauren } & \multirow{2}{*}{ Passage ${ }^{*}$} & \multirow{2}{*}{$\begin{array}{c}\text { Growth } \\
\text { characteristics }\end{array}$} & \multirow{2}{*}{$\begin{array}{c}\text { Cell } \\
\text { morphology }\end{array}$} & \multicolumn{2}{|c|}{$\mathrm{IC}_{50}(\mu \mathrm{g} / \mathrm{mL})$} \\
\hline & & & & & $5 \mathrm{FU}$ & Cisplatin \\
\hline GTX-006 & Diffuse & P6 & Adherent/Suspended & Round & 6.70 & 5.29 \\
\hline GTX-007 & Diffuse & P5 & Adherent/suspended & Round & 7.27 & 4.70 \\
\hline GTX-085 & Intestinal & P4 & Adherent/suspended & Round & 4.39 & $\mathrm{R}$ \\
\hline GTX-086 & ID & P6 & Adherent & Spindle & ND & ND \\
\hline GTX-087 & Intestinal & P5 & Adherent & Round & 2.97 & 3.10 \\
\hline GTX-103 & ID & P5 & Adherent & Polygonal & 4.89 & 3.29 \\
\hline GTX-116 & Intestinal & $\mathrm{P} 2$ & Adherent/suspended & Round & ND & ND \\
\hline GTX-139 & Intestinal & $\mathrm{P} 2$ & Adherent/suspended & Round & ND & ND \\
\hline
\end{tabular}

ID, Indeterminate; ND, Not Done; R, Resistant

* In vivo passage number of xenograft tissue for cell culture 


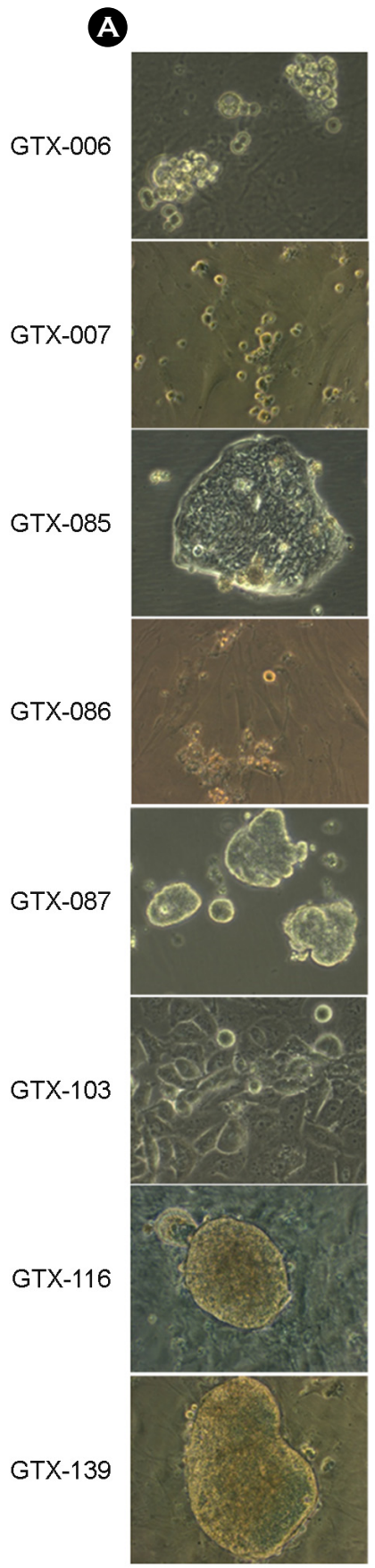

B

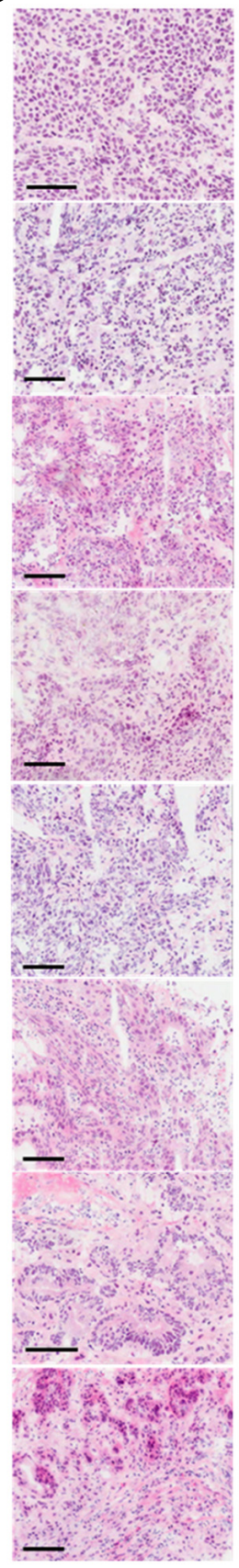

C

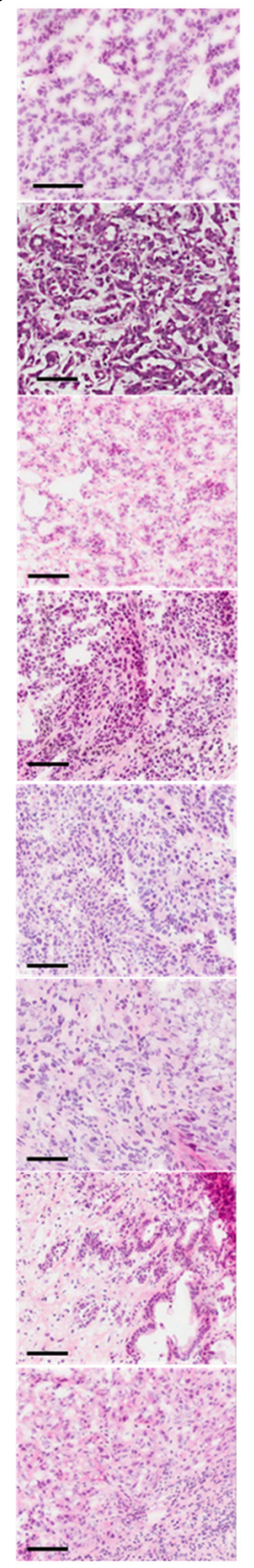

(D)

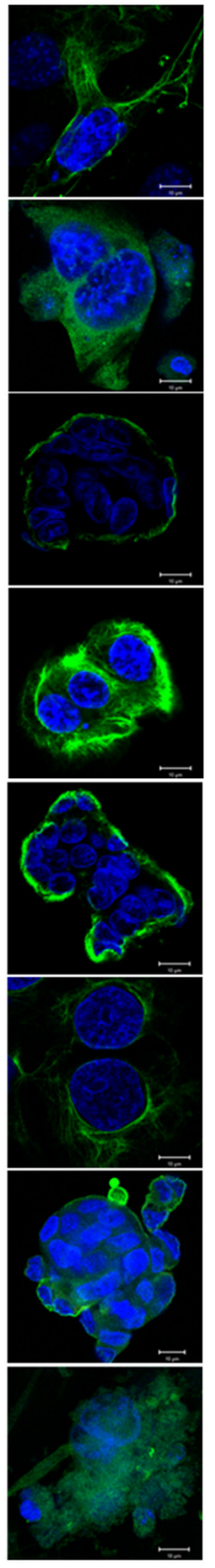

Fig. 1. Morphology of established cell lines. (A) Phase-contrast microscopy of eight established GTX cell lines (magnification 20 $\times$ ). (B) Histology of primary tumors. (C) H\&E histology staining of xenograft tumors from which GTX cell lines originated. Scale bar $=100 \mu \mathrm{m}$. (D) Immunofluorescence of cytokeratin in cell culture. Confocal microscopy images show immunofluorescence of cytokeratin, marked with a FITC-conjugated antibody (green), in eight GTX-cell lines.

lines to antitumor drugs, cells were treated for $72 \mathrm{~h}$ with 5-FU and cisplatin, and the $\mathrm{IC}_{50}$ values were determined (Table 1). GTX-085 cells were resistant to cisplatin, while
GTX-087 was the most sensitive cell line. GTX-085 was the only cell line showing a metastatic potential as described in the next section. Immunocytochemistry of cytokeratin per- 
Table 2. DNA fingerprinting analysis of 16 STR loci of primary gastric tumor tissues (GT) and xenograft tissues (GTX) for newly established cell lines

\begin{tabular}{|c|c|c|c|c|c|c|c|c|c|c|c|c|c|c|c|c|c|}
\hline Locus & $\begin{array}{c}\text { Chromosome } \\
\text { location }\end{array}$ & $\begin{array}{l}\text { GT- } \\
006\end{array}$ & $\begin{array}{c}\text { GTX- } \\
006\end{array}$ & $\begin{array}{l}\text { GT- } \\
007\end{array}$ & $\begin{array}{c}\text { GTX- } \\
007\end{array}$ & $\begin{array}{l}\text { GT- } \\
085\end{array}$ & $\begin{array}{c}\text { GTX- } \\
085\end{array}$ & $\begin{array}{l}\text { GT- } \\
086\end{array}$ & $\begin{array}{c}\text { GTX- } \\
086\end{array}$ & $\begin{array}{l}\text { GT- } \\
087\end{array}$ & $\begin{array}{c}\text { GTX- } \\
087\end{array}$ & $\begin{array}{l}\text { GT- } \\
103\end{array}$ & $\begin{array}{c}\text { GTX- } \\
103\end{array}$ & $\begin{array}{l}\text { GT- } \\
116\end{array}$ & $\begin{array}{c}\text { GTX- } \\
116\end{array}$ & $\begin{array}{l}\text { GT- } \\
139\end{array}$ & $\begin{array}{c}\text { GTX- } \\
139\end{array}$ \\
\hline D8S1179 & 8 & 11,14 & 11,14 & 12,14 & 12,14 & 15,17 & 15,17 & 13,14 & 13,14 & 10,12 & 10,12 & 15 & 15 & 11,12 & 11,12 & 10,11 & 10,11 \\
\hline D21S11 & 21q11.2-q21 & 29,31 & 29,31 & 29,30 & 29,30 & 29,34 & 29,34 & 29,31 & 29,31 & 29,30 & 29,30 & $30,32.2$ & $30,32.2$ & $28,33.2$ & $28,33.2$ & 31.2 & 31.2 \\
\hline D7S820 & $7 \mathrm{q} 11.21-22$ & 8,11 & 8,11 & 10,11 & 10,11 & 10,12 & 10,12 & 10,11 & 10,11 & 10,12 & 10,12 & 8,13 & 8,13 & 8,12 & 8,12 & 10,12 & 10,12 \\
\hline CSF1PO & $5 q 33.3-34$ & 12 & Fail & 12,13 & 12,13 & 8,11 & 8,11 & 12 & 12 & 11 & 11 & 11 & 11 & 8,9 & 8,9 & 9,12 & 9,12 \\
\hline D3S1358 & $3 p$ & 16,17 & 16,17 & 16,17 & 16,17 & 16,17 & 16,17 & 15,16 & 15,16 & 16 & 16 & 15,18 & 18 & 17 & 17 & 13,14 & 13,14 \\
\hline TH01 & $11 \mathrm{p} 15.5$ & 7 & 7 & 6,7 & 6,7 & 9,10 & 9,10 & 7,9 & 7,9 & 9 & 9 & $9,9.3$ & $9,9.3$ & 7,9 & 7,9 & 7,9 & 7,9 \\
\hline D13S317 & $13 q 22-31$ & 10,12 & 10,12 & 10,11 & 10 & 9,14 & 9,14 & 10,12 & 10,12 & 8,9 & 8,9 & 8 & 8 & 11,12 & 11,12 & 8,9 & 8,9 \\
\hline D16S539 & 16q24-qter & 10,11 & Fail & 8,11 & 8,11 & 10,13 & 10,13 & 9,11 & 11 & 9,10 & 9,10 & 11,12 & 12 & 10,11 & 10,11 & 9 & 9 \\
\hline D2S1338 & $2 \mathrm{q} 35-37.1$ & 23 & 23 & 19,23 & 19,23 & 23,24 & 23,24 & 20,24 & 20,24 & 23 & 23 & 23,24 & 23,24 & 20 & 20 & 17,25 & 17,25 \\
\hline D19S433 & $19 \mathrm{q} 12-13.1$ & 13,14 & 13,14 & $13,14.2$ & $13,14.2$ & $11,14.2$ & $11,14.2$ & $14,14.2$ & $14,14.2$ & 13,15 & 13,15 & 14,15 & 14,15 & 11,12 & 11,12 & 12,14 & 12,14 \\
\hline vWA & 12p12-pter & 14,18 & 14,18 & 18,19 & 18,19 & 18,20 & 18,20 & 14,18 & 14,18 & 16,18 & 16,18 & 17,18 & 17,18 & 18,19 & 18,19 & 19,22 & 19,22 \\
\hline TPOX & 2 p23-2per & 8 & 8 & 9,11 & 9,11 & 8,9 & 8,9 & 11 & 11 & 8 & 8 & 8 & 8 & 9,11 & 9,11 & 8,9 & 8,9 \\
\hline D18S51 & $18 \mathrm{q} 21.3$ & 18,19 & Fail & 13,14 & 13,14 & 12,13 & 12,13 & 14 & 14 & 14 & 14 & 17 & 17 & 16,17 & 16,17 & 15,17 & 15,17 \\
\hline X & $\begin{array}{l}\text { X:p22.1-22.3 } \\
\text { Y:p11.2 }\end{array}$ & $\mathrm{XY}$ & $\mathrm{X}$ & $\mathrm{X}, \mathrm{Y}$ & $\mathrm{X}$ & $\mathrm{X}, \mathrm{Y}$ & $\mathrm{X}, \mathrm{Y}$ & $\mathrm{X}, \mathrm{Y}$ & $\mathrm{X}, \mathrm{Y}$ & $\mathrm{X}, \mathrm{Y}$ & $\mathrm{X}, \mathrm{Y}$ & $\mathrm{X}$ & $\mathrm{X}$ & $\mathrm{X}$ & $\mathrm{X}$ & $\mathrm{X}, \mathrm{Y}$ & $\mathrm{X}, \mathrm{Y}$ \\
\hline D5S818 & $5 \mathrm{q} 21-31$ & 10,13 & 10,13 & 9,10 & 9,10 & 8,11 & 8,11 & 7,10 & 7,10 & 9,12 & 12 & 10,11 & 10,11 & 10,11 & 10,11 & 10,12 & 10,12 \\
\hline FGA & $4 q 28$ & 23,25 & 23,25 & 22,23 & 22,23 & 20,21 & 20,21 & 23,26 & 23,26 & 22 & 22 & 20,22 & 20 & 19,21 & 19,21 & 21,22 & 21,22 \\
\hline
\end{tabular}

Table 3. Summary of in vivo tumorigenicity screening analysis of GTX cell lines

\begin{tabular}{|c|c|c|c|c|c|}
\hline \multirow{2}{*}{ Cell lines } & \multicolumn{2}{|c|}{ Subcutaneous } & \multicolumn{3}{|c|}{ Orthotopic } \\
\hline & Number of cells injected & Tumor ${ }^{*}$ & Number of cells injected & Tumor ${ }^{*}$ & Metastasis \\
\hline GTX-006 & $2.46 \times 10^{6}$ & $2 / 3$ & $2.46 \times 10^{6}$ & $2 / 2$ & $\mathrm{x}$ \\
\hline GTX-007 & $1.13 \times 10^{6}$ & $2 / 2$ & $1.13 \times 10^{6}$ & $1 / 2$ & $\mathrm{x}$ \\
\hline GTX-085 & $1.00 \times 10^{6}$ & $1 / 2$ & $1.00 \times 10^{6}$ & $2 / 3$ & Ovary \\
\hline GTX-086 & $2.00 \times 10^{6}$ & $2 / 2$ & ND & ND & ND \\
\hline GTX-087 & $2.50 \times 10^{6}$ & $1 / 2$ & $2.50 \times 10^{6}$ & $0 / 2$ & $x$ \\
\hline GTX-103 & $2.50 \times 10^{6}$ & $0 / 2$ & $2.00 \times 10^{6}$ & $0 / 2$ & $\mathrm{x}$ \\
\hline GTX-116 & $1.00 \times 10^{6}$ & $1 / 1$ & $1.00 \times 10^{6}$ & $1 / 3$ & $\mathrm{x}$ \\
\hline GTX-139 & $2.50 \times 10^{6}$ & $2 / 2$ & $2.50 \times 10^{6}$ & $2 / 3$ & $x$ \\
\hline
\end{tabular}

*Number of mice with tumor growths / total number of mice with injection

formed on the GTX cell lines showed that cytokeratin was expressed in all the GTX cell lines (Fig. 1D).

\section{High tumorigenicity of gastric tumor xenograft cell lines}

The tumorigenicity and metastatic potential of the eight GTX cell lines in mice are summarized in Table 3. Seven cell lines, except GTX-103, showed high tumorigenicity in
4 6 weeks after subcutaneous injection to nude mice (Fig. 2A). In the case of GTX-086, which was derived from an EBV-positive gastric cancer, cells were injected to NSG mice (Fig. 2B). After cells were orthotopically injected into the stomach serosa, five cell lines (GTX-006, GTX-007, GTX085, GTX-116, and GTX-139) formed tumor grafts (Fig. 2C). Among these, the GTX-085 line spontaneously metas- 
(A)

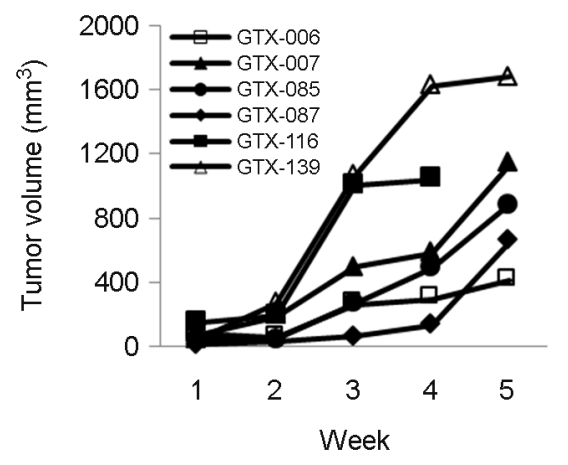

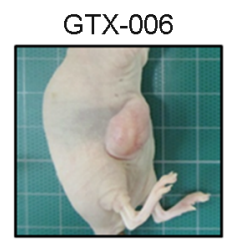

GTX-087

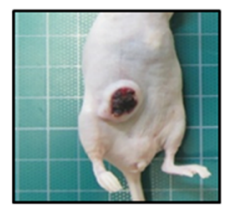

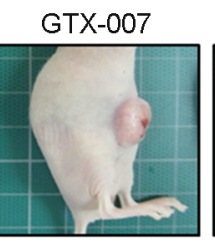

GTX-116

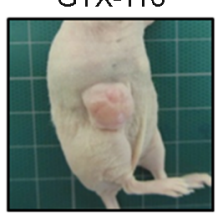

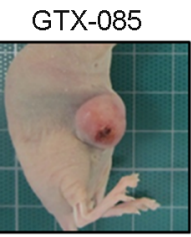

GTX-139

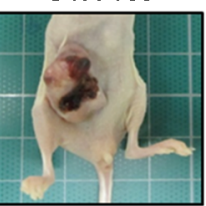

B
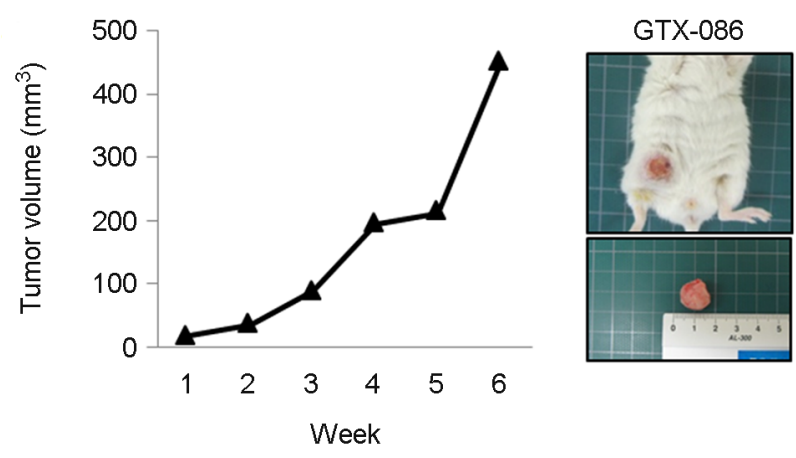

C
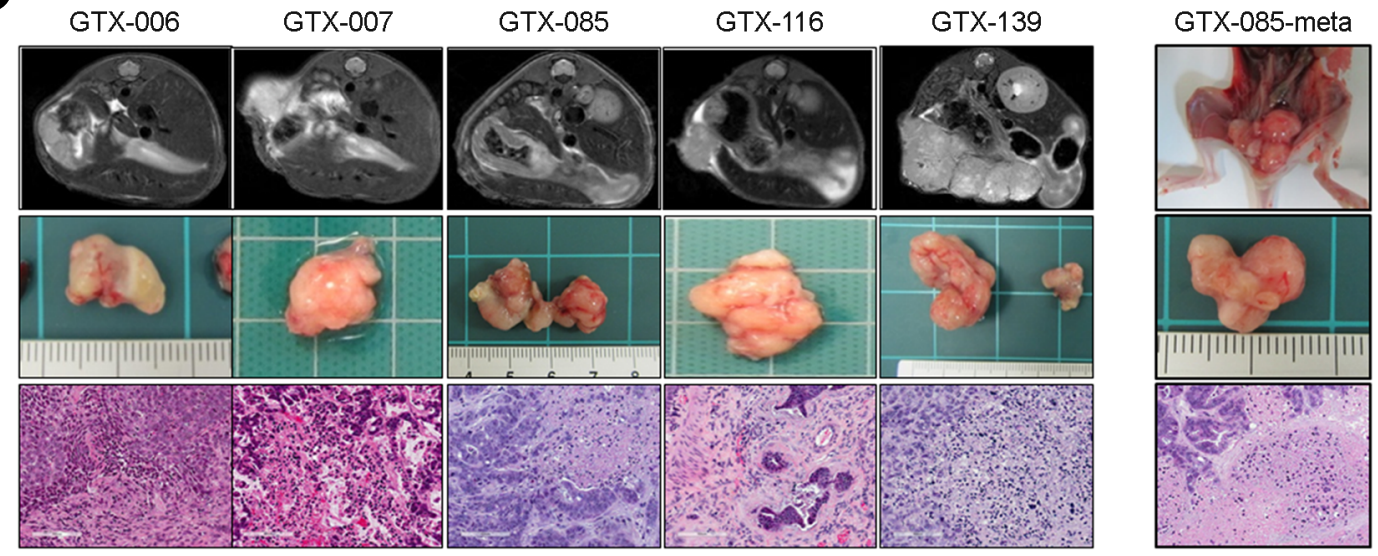

Fig. 2. Screening of eight newly established GTX cell lines for tumorigenicity. (A) Tumor growth after subcutaneous injection of six GTX cell lines (GTX-006, GTX-007, GTX-085, GTX-087, GTX-116, and GTX-139) to nude mice. Mice were sacrificed 4 5 weeks after the injection. (B) Tumor growth after subcutaneous injection of GTX-086 to NSG mice. Mice were sacrificed 6 weeks after the injection. (C) Orthotopic tumorigenicity screening of newly established GTX cell lines. Magnetic resonance (top), macroscopic imaging (middle), and H\&E staining (bottom) of the tumors. Autopsy of mice was carried out $3 \sim 4$ months after the injection.

tasized to the ovary in nude mice (GTX-085-meta; Fig. 2C). Histological features of these xenograft tumors were similar to those of their primary tumors.

\section{Distribution of cancer stem cell markers in GTX cell lines}

Cancer stem cells (CSCs) are regarded as the driving force of tumor formation in vivo, responsible for antitumor 
A

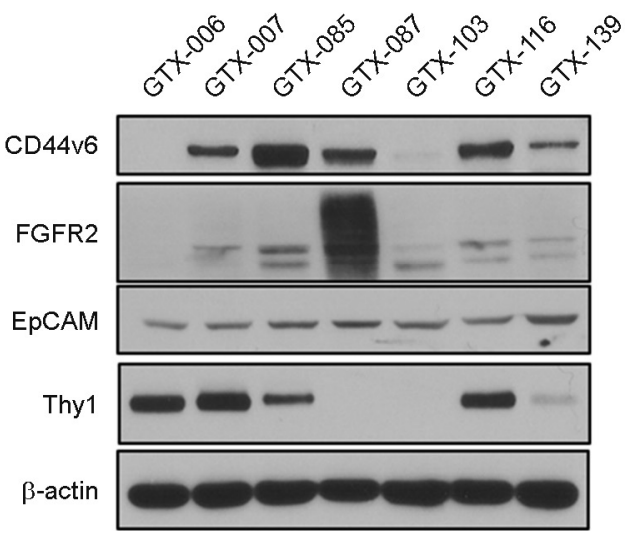

B

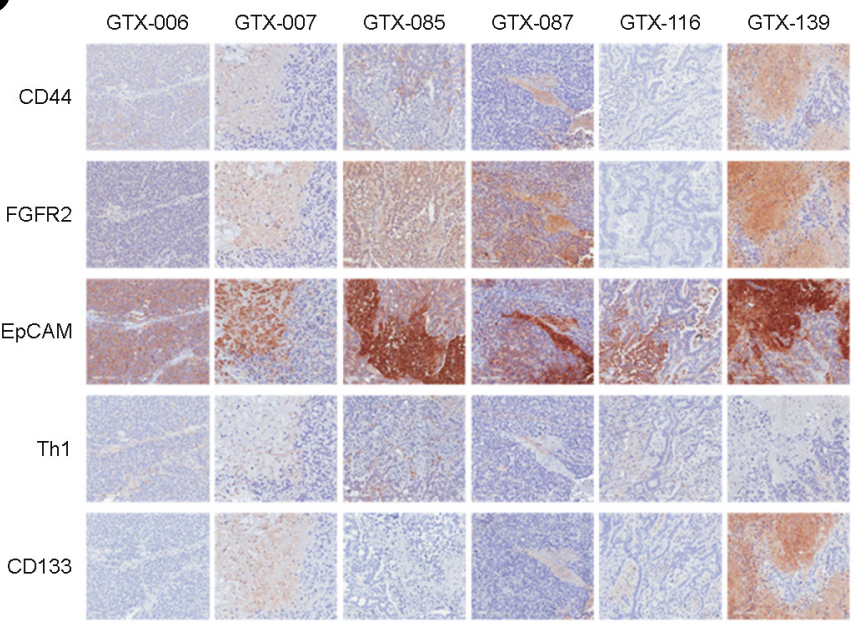

Fig. 3. Expression of cancer stem cell markers in GTX cell lines and xenograft tumors derived from GTX cell lines in nude mice. (A) Western blot of CSC markers in seven GTX cell lines. (B) Immunohistochemistry of CSC markers in xenograft tumor tissues generated by subcutaneous injection from GTX cell lines.

resistance. To identify the presence of gastric CSCs, expression of several markers was evaluated by Western blotting in seven GTX cell lines (except GTX-086) (Fig. 3A). Epithelial cell adhesion molecule (EPCAM) was expressed in all the GTX cell lines, and CD44v6 was expressed in GTX-007, GTX-85, GTX-087, GTX-116, and GTX-139. Fibroblast growth factor receptor 2 (FGFR2) was strongly expressed in GTX-087, and THY1 membrane glycoprotein was expressed in five GTX cell lines, except GTX-087 and GTX-103.

Immunohistochemistry was performed to detect the expression of CSC markers on tumor grafts obtained after subcutaneous injection of GTX cell lines to nude mice (Fig. 3B). EPCAM expression was especially strong in all samples, similar to the cell cultures, and GTX-139, the largest tumor graft formed after the injection (Fig. 2A), displayed distinct expression of CD44v6, FGFR2, and prominin 1 (PROM1, also known as CD133).

\section{DISCUSSION}

Most of the current research on the biology of gastric cancer is based on in vivo and in vitro experiments performed with gastric cancer cell lines. Because authentic cultured cells can be applied to many studies, when tissue specimens are not available, permanent cell lines established from human cancers have played an important role in the understanding of the biology of cancers ( $\mathrm{Ku}$ et al., 2012). The present study describes eight gastric cancer cell lines established from xenograft tumor tissues, which originated from transplantation of primary tissue. Each cell line was shown to be unique and related to the primary tissue at the DNA level, as shown by fingerprinting analysis. None of the cell lines was contaminated by mycoplasmas or bacteria.

Animal models play a crucial role in drug development and research on cancer biology. Various animal models have been established for the investigation of carcinogenic mechanisms and prediction of targeted therapies (Richmond and $\mathrm{Su}, 2008)$. However, generation of animal models using primary tumor tissue is time-consuming and expensive, and thus its application is limited in the research of anticancer drug responses. The eight cell lines from our study showed high tumorigenicity in a few weeks, and their relevant tumor biology mirrored the histochemical and biochemical features of the primary gastric tumors. However, further investigation on the differences between direct culture of primary tissue and xenograft tissue culture cell lines should be performed for elucidating the efficiency of GTX cell lines.

The CD44 isoform overexpression is significantly associ- 
ated with tumor progression, tumorigenicity, growth, metastasis, and prognosis of many carcinomas in humans. Binding of CD44 with its ligands may induce the production of autocrine growth factors, which play an important role in tumor growth (Kodama et al., 2017). Our data from the in vivo tumorigenesis screening of the GTX cell lines revealed that CD44v6 expression was correlated with the tumor growth rate and tumor size. Thus, GTX-006 showed a low level of expression of CD44v6 and low tumorigenicity, while GTX-116 exhibited high tumorigenicity and overexpression of CD44v6.

Metastasis of gastric cancer occurs via hematogenous and lymphogenous routes, peritoneal seeding, and direct invasion. Metastasis is a very complex process, involving multiple consecutive steps (Fidler, 2002). A mouse model of metastatic gastric cancer is an extremely valuable tool to study the metastatic process. In the present study, the mice injected orthotopically with GTX-085 developed tumor growth at the injected position and ovary metastasis. This cell line facilitated research of Krukenberg tumor, poor prognostic features associated with GC metastasis to the ovary (Lee et al., 2015; Jung et al., 2017).

Recent studies have reported an association of EBV with $6 \sim 16 \%$ of gastric cancer cases worldwide (Shibata et al., 1993; van Beek et al., 2002). EBV-positive gastric cancer cell lines such as SNU-719, NCC-24, and YCCE1 have been established and characterized (Oh et al., 2007; Ku et al., 2012). However, attempts to obtain stable EBV-positive cell lines from carcinoma tissues have been largely unsuccessful since the EBV genome tends to be lost during in vitro passages (Lin et al., 1994). Our data on the naturally EBVinfected GTX-086 line, obtained in the present study, also showed that the EBV RNA disappeared as the passage number increased (Supplementary Fig. 2).

In summary, we established eight xenograft cell lines from gastric cancer patient tissues, with their histological and molecular features consistent with those of the primary tumors. Patient-derived xenograft cell lines represent ideal tools for studying tumorigenicity of human stomach cancers in vitro and in vivo. The established GTX cell lines will enable future studies on their responses to different treatments of gastric cancer.

\author{
ABBREVIATIONS \\ aCGH, array comparative genomic hybridization \\ CSC, cancer stem cell \\ EBV, Epstein-Barr virus \\ EPCAM, epithelial cell adhesion molecule \\ FBS, fetal bovine serum \\ FGFR2, fibroblast growth factor receptor 2 \\ FITC, fluorescein isothiocyanate \\ 5-FU, 5-fluorouracil \\ $\mathrm{GC}$, gastric carcinoma \\ gDNA, genomic DNA \\ GTX, gastric tumor xenograft \\ HBSS, Hank's balanced salt solution \\ $H \& E$, hematoxylin and eosin \\ PBS, phosphate-buffered saline \\ $\mathrm{PCR}$, polymerase chain reaction
}

\section{CONFLICT OF INTEREST}

The author declares that there is no conflict of interest.

\section{REFERENCES}

Dangles-Marie V, Pocard M, Richon S, Weiswald LB, Assayag F, Saulnier P, Judde JG, Janneau JL, Auger N, Validire P, Dutrillaux B, Praz F, Bellet D, Poupon MF. Establishment of human colon cancer cell lines from fresh tumors versus xenografts: comparison of success rate and cell line features. Cancer Research. 2007. 67: 398-407.

Daniel VC, Marchionni L, Hierman JS, Rhodes JT, Devereux WL, Rudin CM, Yung R, Parmigiani G, Dorsch M, Peacock CD, Watkins DN. A primary xenograft model of small-cell lung cancer reveals irreversible changes in gene expression imposed by culture in vitro. Cancer Research. 2009. 69: 3364-3373.

Fidler IJ. Critical determinants of metastasis. Seminars in Cancer Biology. 2002. 12: 89-96.

Fukayama M. Epstein-Barr virus and gastric carcinoma. Pathology International. 2010. 60: 337-350.

Jung D, Cho Y, Kim TU, Sa Jeong SH. Gene expression analysis from the normal stomach cells treated with a cancer inducer N-methyl-N'-nitro-N-nitrosoguanidine, MNNG. Biomedical Science Letters. 2017. 23: 30-33.

Kodama H, Murata S, Ishida M, Yamamoto H, Yamaguchi T, Kaida S, Miyake T, Takebayashi K, Kushima R, Tani M. Prognostic 
impact of CD44-positive cancer stem-like cells at the invasive front of gastric cancer. British Journal of Cancer. 2017. 116: 186-194.

Ku JL, Kim KH, Choi JS, Kim SH, Shin YK, Chang HJ, Bae JM, Kim YW, Lee JH, Yang HK, Kim WH, Jeong SY, Park JG. Establishment and characterization of six human gastric carcinoma cell lines, including one naturally infected with Epstein-Barr virus. Cellular Oncology (Dordrecht). 2012. 35: 127-136.

Lee EK, Song KA, Chae JH, Kim KM, Kim SH, Kang MS. GAGE12 mediates human gastric carcinoma growth and metastasis. International Journal of Cancer. 2015. 136: 2284 -2292 .

Lin CT, Dee AN, Chen W, Chan WY. Association of Epstein-Barr virus, human papilloma virus, and cytomegalovirus with nine nasopharyngeal carcinoma cell lines. Laboratory Investigation. 1994. 71: 731-736.

Nakanishi H, Yasui K, Ikehara Y, Yokoyama H, Munesue S, Kodera

Y, Tatematsu M. Establishment and characterization of three novel human gastric cancer cell lines with differentiated intestinal phenotype derived from liver metastasis. Clinical and Experimental Metastasis. 2005. 22: 137-147.

Oh ST, Cha JH, Shin DJ, Yoon SK, Lee SK. Establishment and characterization of an in vivo model for Epstein-Barr virus positive gastric carcinoma. Journal of Medical Virology. 2007. 79: 1343-1348.

Park JG, Frucht H, LaRocca RV, Bliss DP, Jr., Kurita Y, Chen TR, Henslee JG, Trepel JB, Jensen RT, Johnson BE, Bang YJ, Kim JP, Gazdar AF. Characteristics of cell lines established from human gastric carcinoma. Cancer Research. 1990. 50: 2773 -2780 .

Park JG, Yang HK, Kim WH, Chung JK, Kang MS, Lee JH, Oh JH, Park HS, Yeo KS, Kang SH, Song SY, Kang YK, Bang YJ, Kim YH, Kim JP. Establishment and characterization of human gastric carcinoma cell lines. International Journal of Cancer. 1997. 70: 443-449.

Richmond A, Su Y. Mouse xenograft models vs gem models for human cancer therapeutics. Disease Models \& Mechanisms. 2008. 1: 78-82.

Shibata D, Hawes D, Stemmermann GN, Weiss LM. Epstein-Barr virus-associated gastric adenocarcinoma among Japanese Americans in Hawaii. Cancer Epidemiology, Biomarkers \&
Prevention. 1993. 2: 213-217.

Shin HR, Jung KW, Won YJ, Park JG, 139 KCCR-affiliated Hospitals. 2002 annual report of the Korea Central Cancer Registry: based on registered data from 139 hospitals. Cancer Research and Treatment. 2004. 36: 103-114.

Shridhar R, Almhanna K, Hoffe SE, Fulp W, Weber J, Chuong MD, Meredith KL. Increased survival associated with surgery and radiation therapy in metastatic gastric cancer: a Surveillance, Epidemiology, and End Results database analysis. Cancer. 2013. 119: 1636-1642.

Ushijima T, Sasako M. Focus on gastric cancer. Cancer Cell. 2004. 5: 121-125.

van Beek J, zur Hausen A, Kranenbarg EK, Warring RJ, Bloemena E, Craanen ME, van de Velde CJ, Middeldorp JM, Meijer CJ, van den Brule AJ. A rapid and reliable enzyme immunoassay PCR-based screening method to identify EBV-carrying gastric carcinomas. Modern Pathology. 2002. 15: 870-877.

Yanagihara K, Seyama T, Tsumuraya M, Kamada N, Yokoro K. Establishment and characterization of human signet ring cell gastric carcinoma cell lines with amplification of the c-myc oncogene. Cancer Research. 1991. 51: 381-386.

Yanagihara K, Tanaka H, Takigahira M, Ino Y, Yamaguchi Y, Toge T, Sugano K, Hirohashi S. Establishment of two cell lines from human gastric scirrhous carcinoma that possess the potential to metastasize spontaneously in nude mice. Cancer Science. 2004. 95: 575-582.

Yoo TH, Lee MH, Min Park1, Lee J, Woo HJ, Kim HW, Yang JY, Kwon HJ, Yeon MJ, Kim JB. Detection of EBV-encoded Small RNA from Diffuse Large B-cell Lymphoma Patients by RT-PCR Method. Biomedical Science Letters. 2015. 21: 227-232.

Young LS, Murray PG. Epstein-Barr virus and oncogenesis: from latent genes to tumours. Oncogene. 2003. 22: 5108-5121.

https://doi.org/10.15616/BSL.2017.23.3.238

Cite this article as: Song KA, Park JH, Kim HJ, Kang MS, Kim SY. Establishment of Highly Tumorigenic Human Gastric Carcinoma Cell Lines from Xenograft Tumors in Mice. Biomedical Science Letters. 2017. 23: 238-250. 